Original Article

\title{
Customer satisfaction analysis of the healthy elderly to investigate the association among happiness, health status, and well-being using the Happiness \& Health Feeling Scale
}

\author{
Kaori Teraoka, $\mathrm{PT}^{1)^{*}}$, Minako Suzuki, $\mathrm{PhD}^{1)}$, Yuito Ueda ${ }^{1)}$, Norio Shimanouchi, MD, PhD ${ }^{2)}$ \\ 1) Graduate School of Health and Sports Science, Faculty of Health and Sports Science, Juntendo \\ University: Hiraga-gakuendai, Inzai, Chiba 270-1695, Japan \\ 2) Faculty of International Liberal Arts, Juntendo University, Japan
}

\begin{abstract}
Purpose] In this study, we aimed to analyze customer satisfaction as a tool to investigate the association among happiness, health status, and well-being using the Happiness \& Health Feeling Scale. [Participants and Methods] We included 17 elderly participants and measured the happiness and health statuses using the Happiness $\&$ Health Feeling Scale. We analyzed customer satisfaction by correlating subjective well-being with the questionnaire scores. [Results] The results showed a negative correlation between subjective well-being and the score on each questionnaire (correlation coefficient $=-0.476$ ). The elderly participants showed lower scores associated with self-esteem, including external appreciation and self-love, whereas high scores associated with eating and pleasure. The Cronbach's alpha was 0.814. [Conclusion] This study showed an inverse correlation between Happiness \& Health Feeling Scale score and well-being, presumably because of low scores associated with self-esteem, which should be prioritized for improvement. The additional use of customer satisfaction analysis using the Happiness \& Health Feeling Scale could be helpful to elucidate the subjective association between happiness and health-related factors.

Key words: Happiness and Health Feeling Scale, Well-being, Customer satisfaction analysis
\end{abstract}

(This article was submitted Jan. 24, 2019, and was accepted Jul. 4, 2019)

\section{INTRODUCTION}

Maintaining health behaviors is important to enhance well-being, although the assessment is difficult because it is associated with not only basic desires such as eating and sleeping, but also with various psychological factors, such as beliefs, expectations, motives, values, perceptions, and other cognitive factors ${ }^{1}$. Happiness and Health Scale (2HFS) has been developed by Suzuki and Shimanouchi for adults and college students, as a useful tool to quantitatively and comprehensively evaluate health behaviors ${ }^{2}$, but the assessment is based on a simple aggregated scoring, which makes it difficult to assess mutual relationships among scales. To assess such relationships, one of the convenient tools is customer satisfaction (CS) analysis generally used to interpret CS and its importance in a two-dimensional scale ${ }^{3-10}$. Therefore, this study aimed to investigate the reliability and validity of the combined use of 2HFS with CS analysis to elucidate global relationships between multiple factors relevant to health and happiness, using a small sample of the elderly population.

*Corresponding author. Kaori Teraoka (E-mail: teraoka0816@yahoo.co.jp)

(C2019 The Society of Physical Therapy Science. Published by IPEC Inc.

(c) (i) $\odot$ This is an open-access article distributed under the terms of the Creative Commons Attribution Non-Commercial No DerivacC. 


\section{PARTICIPANTS AND METHODS}

Participants were 17 elderly persons over 65 years ( 3 male and 14 female individuals) living in the Tokyo metropolitan area. Happiness and health status were measured once using the 2HFS including 18 questionnaires regarding eating, sleep, exercise, laughter, pleasure, self-esteem, and the sense of happiness as shown in Table 1. All participants provided written informed consent prior to participation in this study. The study was conducted with the approval of the Institutional Review Board of Juntendo University (No. 30-43). Subjective well-being was obtained by calculating correlation coefficient of scores on each of the 2HFS questionnaires with current sense of happiness. CS analysis was performed by analyzing correlation of subjective well-being with scores on each of the questionnaires. To visualize the association of these 18 scores with correlation coefficient between subjective well-being, these scores were plotted two-dimensionally, and the correlation coefficient was measured. Reliability was assessed with Cronbach's alpha. All data analyses were performed using EZR ${ }^{11)}$.

\section{RESULTS}

The CS analysis graph depicted in Fig. 1 shows that factors related to eating, exercise, and pleasure showed both high scores and high well-being in the first quadrant, termed the emphasis maintenance field. The factors related to self-esteem, including external appreciation and self-love, showed low scores and high well-being in the fourth quadrant, termed the priority improvement field. Age-related functional decline such as sweating locates in the third quadrants. Overall, a negative correlation was found between subjective well-being and the scores on 18 items in the 2 HFS scale (correlation coefficient $=-0.476$, $95 \%$ confidence interval -0.772 to -0.0123 ). The Cronbach's alpha was 0.814 .

Table 1. Happiness and Health Feeling Scale (2HFS)-related questionnaire

\begin{tabular}{|c|c|c|c|c|c|c|c|c|}
\hline \multicolumn{6}{|c|}{$\begin{array}{l}\text { Please answer the following questions by indicating the numbers which apply to you } \\
\text { Please answer every day } \\
\text { Evening is recommended }\end{array}$} & \multirow{2}{*}{$\begin{array}{c}\text { Sub- } \\
\text { total }\end{array}$} & \multirow{2}{*}{$\begin{array}{c}\text { Total } \\
-\end{array}$} & \multirow{2}{*}{$\begin{array}{c}\text { Type } \\
\text { - }\end{array}$} \\
\hline Question & Yes & $\begin{array}{l}\text { I think } \\
\text { so }\end{array}$ & $\begin{array}{l}\text { I cannot say } \\
\text { either way }\end{array}$ & $\begin{array}{l}\text { I do not } \\
\text { think so }\end{array}$ & No & & & \\
\hline 1. I got a satisfactory feeling with food & 5 & 4 & 3 & 2 & 1 & & \multirow{3}{*}{\multicolumn{2}{|c|}{$\begin{array}{c}\text { A } \\
\text { Good } \\
\text { eating }\end{array}$}} \\
\hline 2. I got a tasty feeling and a fun of eating & 5 & 4 & 3 & 2 & 1 & & & \\
\hline 3. I paid attention to a nutritional balance & 5 & 4 & 3 & 2 & 1 & & & \\
\hline 4. I got a good sleep last night & 5 & 4 & 3 & 2 & 1 & & \multirow{3}{*}{\multicolumn{2}{|c|}{$\begin{array}{l}\text { B } \\
\text { Good } \\
\text { sleep }\end{array}$}} \\
\hline 5. I got a good arousal in the morning & 5 & 4 & 3 & 2 & 1 & & & \\
\hline 6. I felt restorative and positive & 5 & 4 & 3 & 2 & 1 & & & \\
\hline 7. I walked approximately 30 minutes & 5 & 4 & 3 & 2 & 1 & & \multirow{3}{*}{\multicolumn{2}{|c|}{$\begin{array}{c}\mathrm{C} \\
\text { Good } \\
\text { exercise }\end{array}$}} \\
\hline 8. I got a light move & 5 & 4 & 3 & 2 & 1 & & & \\
\hline 9. I got a good sweat & 5 & 4 & 3 & 2 & 1 & & & \\
\hline 10. I laughed a lot & 5 & 4 & 3 & 2 & 1 & & \multirow{3}{*}{\multicolumn{2}{|c|}{$\begin{array}{c}\text { D } \\
\text { Good } \\
\text { laughter }\end{array}$}} \\
\hline 11. I kept smiled & 5 & 4 & 3 & 2 & 1 & & & \\
\hline 12. I got a funny experience & 5 & 4 & 3 & 2 & 1 & & & \\
\hline 13. I enjoyed my hobbies and amusement & 5 & 4 & 3 & 2 & 1 & & \multirow{3}{*}{\multicolumn{2}{|c|}{$\begin{array}{c}\mathrm{E} \\
\text { Good } \\
\text { pleasure }\end{array}$}} \\
\hline 14. I had a relationship with my family or friends & 5 & 4 & 3 & 2 & 1 & & & \\
\hline 15. I had a sense of fulfillment in my daily life & 5 & 4 & 3 & 2 & 1 & & & \\
\hline 16. I could love myself & 5 & 4 & 3 & 2 & 1 & & \multirow{3}{*}{\multicolumn{2}{|c|}{$\begin{array}{l}\text { F } \\
\text { Good } \\
\text { living }\end{array}$}} \\
\hline 17. I felt appreciated or needed by someone & 5 & 4 & 3 & 2 & 1 & & & \\
\hline 18. I felt having a good life and livelihood & 5 & 4 & 3 & 2 & 1 & & & \\
\hline \multirow[t]{2}{*}{ What is your today's sense of happiness? } & $\begin{array}{l}\text { Very } \\
\text { happy }\end{array}$ & Happy & Average & $\begin{array}{l}\text { Slightly } \\
\text { unhappy }\end{array}$ & Unhappy & - & - & - \\
\hline & 5 & 4 & 3 & 2 & 1 & & & - \\
\hline
\end{tabular}




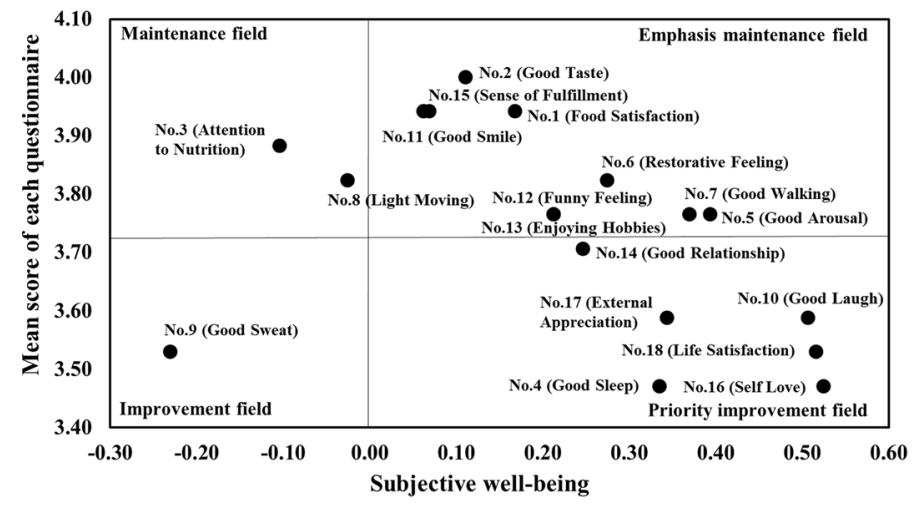

Fig. 1. Customer satisfaction (CS) analysis graph plotted on two-dimensional coordinates. The average value of the 2 HFS scores for each questionnaire are plotted on the vertical axis, and the value of subjective well-being, calculated with correlation coefficient between each of the 2HFS subscale scores and current happiness scores are shown on the horizontal axis of the CS analysis graph.

\section{DISCUSSION}

The present study showed a negative correlation between factors of 2HFS scales and subjective well-being among elderly participants using CS analysis. Among the factors of 2HFS scales, those related to basic human desires, i.e., eating, exercise, and pleasure showed both high 2HFS scores and high well-being in the first quadrant, whereas factors related to self-esteem, including self-love, and external appreciation, showed low 2HFS scores and high well-being in the fourth quadrant. The result suggested that the participants of the present study had already satisfied their basic human desires, although they had not yet satisfied factors relating to self-esteem and wished to improve. A previous study using the combination of 2 HFS survey with factor analysis for university students also suggested that self-esteem is one of the important factors of the sense of happiness, which is consistent with the findings of the present study ${ }^{2}$. In terms of the validity of this methodology, the Cronbach's alpha was 0.814 , which could be enough for its reliability. The present method is also beneficial in terms of its simplicity of analysis and interpretation through two-dimensional visualization. This combined method was also applied in previous studies investigating the association of well-being with various physical functions, such as falls in elderly people ${ }^{12-15)}$, communication exercises $^{3,16,17)}$, and teaching spiritual care ${ }^{18)}$. Not only diagnosis of physical functions but more comprehensive diagnoses, including psychological factors, happiness, and self-esteem, will lead to detection of life-related problems and providing guidance in positive perspectives to maintain a healthier lifestyle. The present study has several limitations. First, because the study surveyed a small number of elderly participants with the age of $77.8 \pm 77.6$ (mean, SD), and $82.4 \%$ of them were females, the results may not be generalized to other populations. Second, because this study was based on cross-sectional data, it was not possible to infer causality among factors. Further research will be required to verify causal relationship between them through some intervention, e.g. happiness and health-related educational programs.

\section{Conflict of interest}

Authors declare no conflicts of interest associated with this manuscript.

\section{REFERENCES}

1) Gochman DS: Labels, systems and motives: some perspectives for future research and programs. Health Educ Q, 1982, 9: 263-270. [Medline] [CrossRef]

2) Suzuki M, Shimanouchi N, Hirosawa M: Examining reliability and validity of the Happiness \& Health Feeling Scale (2HFS) for university students. Jpn J Health Educ Promot, 2014, 22: 324-332.

3) Dewi FD, Sudjana G, Oesman YM: Patient satisfaction analysis on service quality of dental health care based on empathy and responsiveness. Dent Res J Isfahan, 2011, 8: 172-177. [Medline] [CrossRef]

4) Kimura M, Usami E, Iwai M, et al.: Oral anticancer agent medication adherence by outpatients. Oncol Lett, 2014, 8: 2318-2324. [Medline] [CrossRef]

5) Ko MS, Lee WH: Analysis of the relationships among perceived service encounter quality, service value, satisfaction and behavioral intention for physical therapy patients. J Phys Ther Sci, 2017, 29: 2000-2003. [Medline] [CrossRef]

6) Lee YC, Wang YC, Lu SC, et al.: An empirical research on customer satisfaction study: a consideration of different levels of performance. Springerplus, 2016, 5: 1577. [Medline] [CrossRef]

7) Lin FH, Tsai SB, Lee YC, et al.: Empirical research on Kano's model and customer satisfaction. PLoS One, 2017, 12: e0183888. [Medline] [CrossRef]

8) Mkpojiogu EO, Hashim NL: Understanding the relationship between Kano model's customer satisfaction scores and self-stated requirements importance. 
Springerplus, 2016, 5: 197. [Medline] [CrossRef]

9) Sanghani RM, Moler AK: Improving consumer satisfaction with addiction treatment: an analysis of alumni preferences. J Addict, 2015, 2015: 509864. [Medline] [CrossRef]

10) Ho $\mathrm{CH}$, Wene $\mathrm{HC}$, Chu CM, et al.: Importance-satisfaction analysis for primary care physicians' perspective on EHRs in Taiwan. Int J Environ Res Public Health, 2014, 11: 6037-6051. [Medline] [CrossRef]

11) Kanda Y: Investigation of the freely available easy-to-use software 'EZR' for medical statistics. Bone Marrow Transplant, 2013, 48: 452-458. [Medline] [CrossRef]

12) Costello E, Edelstein JE: Update on falls prevention for community-dwelling older adults: review of single and multifactorial intervention programs. J Rehabil Res Dev, 2008, 45: 1135-1152. [Medline] [CrossRef]

13) Lord SR, Castell S, Corcoran J, et al.: The effect of group exercise on physical functioning and falls in frail older people living in retirement villages: a randomized, controlled trial. J Am Geriatr Soc, 2003, 51: 1685-1692. [Medline] [CrossRef]

14) Fukukawa Y, Kozakai R, Niino N, et al.: Social support as a moderator in a fall prevention program for older adults. J Gerontol Nurs, 2008, 34: 19-25, quiz 26-27. [Medline] [CrossRef]

15) Suzuki T, Kim H, Yoshida H, et al.: Randomized controlled trial of exercise intervention for the prevention of falls in community-dwelling elderly Japanese women. J Bone Miner Metab, 2004, 22: 602-611. [Medline] [CrossRef]

16) June A, Andreoletti C: Participation in intergenerational service-learning benefits older adults: a brief report. Gerontol Geriatr Educ, 2018, 1-6. [Medline] [CrossRef]

17) Mishima SM, Campos AC, Matumoto S, et al.: Client satisfaction from the perspective of responsiveness: strategy for analysis of universal systems? Rev Lat Am Enfermagem, 2016, 24: e2674. [Medline] [CrossRef]

18) Galloway S, Hand MW: Spiritual immersion: developing and evaluating a simulation exercise to teach spiritual care to undergraduate nursing students. Nurse Educ, 2017, 42: 199-203. [Medline] [CrossRef] 